\title{
Lokala genuskontrakt i förändring
}

\section{Av Susanne Johansson, forskningsprogrammet Svensk modell $i$ förändring, Arbetslivsinstitutet och Uppsala universitet}

I denna artikel presenteras några resultat från ett forskningsprojekt som bland annat resulterade i en avhandling med titeln Genusstrukturer och lokala välfärdsmodeller - Fyra kommuner möter omvandlingen av den offentliga sektorn (Johansson 2000). Avhandlingen behandlar 1990-talets omvandling av den offentliga sektorn ur ett genusperspektiv. I avhandlingen analyseras såväl orsaker till strukturomvandlingen av offentliga sektorn som effekter av förändringsprocesserna. I denna artikel fokuseras främst sambandet mellan genuskontrakt och välfärdsmodeller som ett exempel på hur en kulturgeografisk studie påverkas av ett feministisk angreppssätt.

För att förstå effekter av en strukturomvandling när det gäller de offentliga verksamheterna är det viktigt att kartlägga och fastställa de förhållanden som rådde mellan stat, marknad, familj och övriga delar av det civila samhället vad gäller välfärdsrelaterade tjänster när omvandlingsprocessen startade. En grundläggande princip för välfärdsrelaterade tjänster i Sverige har varit att de varit både offentligt organiserade och producerade vilket till viss del förklarar det ofta synonyma användandet av begreppen offentliga tjänster och välfärdstjänster. Detta har i Sverige lett till framväxten av en stor offentlig sektor och även en hög förvärvsfrekvens för kvinnor. Den svenska utvecklingen analyseras här med utgångspunkt i det samspel mellan socialpolitiska stöd och de välfärdstjänster som uppstod och som är en betydande del av kvinnors arbetsmarknad.

Studien hade följaktligen som ambition att bidra till kunskapen om vilka effekter 1990-talets omvandling av offentlig sektor i Sverige har haft på kvinnors största delarbetsmarknad, med fokus på den kommunala verksamheten. Särskild vikt lades vid de lokala skillnaderna när det gäller sysselsättningsutvecklingen inom sektorn och graden av omorganisation.

\section{Studiens syfte}

Studien hade ett huvudsyfte och två delsyften. Huvudsyftet kan sammanfattas i det övergripande målet att analysera de under 1990-talet förändrade förutsättningarna för produktionen av offentliga tjänster och dess effekter på främst kvinnors sysselsättningsmöjligheter. Särskilt analyserades den könsvisa arbetsdelningen på de utvalda lokala arbetsmarknaderna, i vilka kvinnors största delarbetsmarknad, nämligen primärkommunal sektor valdes ut.

För att förstå kvinnors villkor på arbetsmarknaden är det av fundamental betydelse att få en klar uppfattning om hur arbetsfördelningen vad gäller de välfärdsrelaterade tjänsterna ser ut mellan familj, stat, marknad och övriga delar av det civila samhället. I ljuset av detta antagande var studiens ena delsyfte att analysera 1990-talstendenserna i förhållande till den välfärdsmodell som Sverige tillhör, den så kallade Skandinaviska välfärdsmodellen (Esping-Andersen 1991). Ett antagande i detta avseende var att 1990-talets avreglering och decentralisering av de offentliga verksamheterna lett till att det inte längre är fråga om en enda välfärdsmodell utan att det växt fram parallellt existerande lokala välfärdsmodeller. I detta sammanhang diskuteras om den skandinaviska välfärdsmodellen bör omdefinieras.

Den ansats som valts för att studera sambandet mellan välfärdsstaten och kvinnors arbetsmarknad utgår från Hirdmans teorier om genuskontrakt. Hirdman urskiljer olika samhälleliga genuskontrakt, definierat som "den sociala norm som vid olika tidpunkter 
existerar vad gäller kön: plats, sysslor och egenskaper" (Hirdman 1990) Hirdman använder sig av begreppet genuskontrakt för att teoretisera maktrelationerna mellan män och kvinnor. Kontrakten bygger på en osynlig relation bestående av en övertagen, kulturellt nedärvd överenskommelse, ett slags (tvångs)band mellan två enheter. Det är viktigt att poängtera att kontraktet inte ska tolkas som ett kontrakt skrivet mellan två likvärdiga parter med samma möjligheter att påverka kontraktets innehåll. Hirdman poängterar att genuskontrakt bör uppfattas som en förenkling av en komplicerad verklighet och kan användas för att renodla och analysera det komplexa beroendet mellan män och kvinnor.

Den svenska välfärdsstatens historia delas in i olika epoker eller rättare sagt kontrakt; Husmoderskontraktet eller den andra historiska kompromissen (1930-60), Övergångsfasen (1950-60-talet), Jämlikhetskontraktet (1965-75/80), Jämställdhetskontraktet (1975/80-) (Hirdman 1990). Den konfliktlösning som valdes vid varje given tidpunkt ska, enligt Hirdmans mening, förstås i spänningsfältet mellan de integrerande krafterna (ekonomiska, demokratiska) och de segregerande (genus) krafterna.

Genuskontraktsteorin formulerades i syfte att förklara ett historiskt förlopp, nämligen den svenska välfärdsstatens uppbyggnad. Samhällsutvecklingen gjorde att det rådande kontraktet kom i kris och det nya samhället krävde en "omförhandling" av relationerna mellan könen (Hirdman 1992). Hirdman skriver:

\footnotetext{
"När det gällde män och kvinnor, Man och Kvinna, var det som om det i praktiken fördes regelrätta förhandlingar om i stort sett varje samhälleligt (och privat) område och vilken plats kvinnor skulle ha. Det var emellertid oftast förhandlingar mellan män om kvinnor." (Hirdman 1992 s 6)
}

Den konfliktlösning som valdes vid den svenska välfärdsstatens uppkomst kännetecknas av att staten utgjorde en viktig partner i det kontrakt mellan könen som framförhandlades. Detta är en av de viktigaste dimensionerna av den svenska välfärdsstaten, en dimension som enligt Hirdman gör det möjligt att tala om "genuskontrakt på en abstrakt politisk nivå, dvs politiska, normerande föreställningar om män och kvinnor med bland annat konkreta styrande lagar, institutioner och reformer som följd" (Hirdman 1992 s 6). I och med 1990talets decentraliserings process har mycket av beslutsfattandet vad gäller inriktningen och organisationen av välfärdstjänster förts ner på den kommunala nivån. Detta gör det angeläget att anlägga ett lokalt perspektiv på studier av välfärdsstatens utformning och innehåll eftersom förhandlingarna om arbetsdelningen mellan könen alltmer sker mellan kvinnor, män och den lokala staten. Det andra delsyftet är därför att försöka förklara effekterna av pågående omstrukturering i termer av sambandet mellan de lokala välfärdsmodellerna och de lokala genuskontrakten. Det vill säga, i vilken utsträckning kan de lokala utfallen förklaras med det förhandlingsläge som råder mellan kvinnor, män och den lokala staten? Kommunens sociala, ekonomiska och geografiska strukturer samspelar så att de bygger upp genusstrukturerade relationer med sin bas i det dagliga livet. Och eftersom platser skiljer sig åt vad gäller dessa strukturer så skapas skilda genusidentiteter på olika platser.

\section{Välfärd i förändring}

Vid en analys av 1900-talets samhällsutveckling i Sverige framstår framväxten av välfärdsstaten och den offentliga sektorns expansion som en av de mest fundamentala förändringarna. På samma sätt kännetecknas paradoxalt nog sista decenniet av samma århundrade av ett ifrågasättande av den svenska välfärdsmodellen, en ökad tilltro på marknadskrafter när det gäller välfärdsproduktionen och en växande kritik mot offentliga sektorns verksamheter, men kanske framförallt storleken på de offentliga verksamheterna. Det utmärkande för svensk ekonomi under 1990-talets första hälft var en stor och snabbt ökande statsskuld och ett stort budgetunderskott. Det huvudsakliga sättet att angripa detta problem, så som det redovisades i budgetpropositioner under dessa år, var sänkning av de offentliga utgifterna främst genom rationaliseringar och effektiviseringar inom den offentliga sektorn samt genom skattehöjningar (Regeringens budgetförslag (1989/90), 
Regeringens budgetförslag 1991/92:150, Regeringens budgetförslag 1992/1993). Den offentliga sektorns storlek påstods vara en avgörande anledning till Sveriges ekonomiska kris och debatten spände mellan åsikten att den offentliga sektorn behövde krympas och uppfattningen att det krävdes en mer eller mindre total nedmontering av offentliga sektorn och en välfärd byggd på ett individuellt försäkringssystem (Antman 1993).[1] En av de viktigaste samhällspolitiska frågorna under 1990-talet var, och är fortfarande, hur vården, omsorgen och utbildningen ska finansieras och i vilken regi den ska drivas.

\section{Kris i genuskontraktet}

Genuskontraktet påverkas av, och påverkar i sin tur, fördelningen av de reproduktiva uppgifterna mellan stat, marknad och familj. Forskning om beroendeförhållandet mellan den svenska välfärdsstaten, kvinnorna och männen påvisar ett dubbelt beroende mellan staten och kvinnorna, både i form av behovet av välfärdstjänster och av att kvinnor i stor utsträckning har staten som arbetsgivare. Flera politiska reformer har stött och underlättat kvinnligt förvärvsarbete, vilket hade till följd att den offentliga sektorn expanderade och skapade nya jobb som ofta besattes av just kvinnor, under den offentliga sektorns expansiva fas. Den offentliga sektorn stod strängt taget för huvuddelen av sysselsättningstillväxten från tidigt 1960-tal, och nästan hela ökningen har utgjorts av kvinnor. Resultatet blev att den offentliga sektorn i stor utsträckning kom att bestå av kvinnodominerade arbetsplatser. Sverige har också utmärkts av en kontinuerligt ökad kvinnlig förvärvsfrekvens från 1960 och fram till 1991 då trenden bröts (SCB:s årliga sysselsättningsstatistik 1990-1995). Det fanns ett stort behov av arbetskraft inom den offentliga sektorn under 1980-talet, vilket fick till följd att kvinnors och mäns sysselsättningsnivåer blev närmast identiska. När sedan neddragningarna inom offentlig sektor tog fart på allvar ledde detta till att den över trettioåriga trenden bröts och kvinnornas sysselsättningsnivå minskade med 10 procentenheter mellan 1990 och 1995. Antalet kvinnor inom den offentliga sektorn minskade med 128000 på tre år (1992-1995), en minskning med 11 procent (Lagergren, M. Batljan, I. \& Zavixic, S 1997).

Från att tidigare ha betraktats som en resurs som skulle uppmuntras till förvärvsarbete för att täcka behovet av arbetskraft inom svensk industri och den expanderande offentliga sektorn, framställs nu den arbetsmarknad som kvinnor främst arbetar inom som ett ekonomiskt problem (Freeman, R. Swedenborg, B. \& Topel, R 1995). Under 1990-talets första hälft genomdrevs en rad reformer som innebar att villkoren för kvinnorna förändrades på olika nivåer. Det skedde en gradvis försämring av olika socialpolitiska stöd (bl a sänktes ersättningen vid sjuk- föräldra- och arbetslöshetsförsäkring successivt[2]). Samtidigt har tusentals arbetstillfällen försvunnit inom den kvinnodominerade offentliga sektorn, vilket dessutom i många kommuner inneburit att utbudet av exempelvis barnomsorg har minskat eller att kvalitén försämrats. Den omvandling av den offentliga sektorn som pågick under 1990-talet påverkade sektorn både som arbetsmarknad och som välfärdsproducent. Förändringarna innebar en underminering av två viktiga grundpelare, arbetstillfällen och tillgång till barnomsorg, som gjort att kvinnor i Sverige har uppnått ett relativt stort mått av ekonomiskt oberoende. Det finns dessutom anledning att diskutera om genuskontraktet genom 1990-talets decentraliseringsprocess alltmer kommit att dikteras på en lokal nivå.

Frågan är hur reformarbetet tog sig uttryck i de olika kommunerna när det passerat de kommunala beslutsorganen och vad det i sin tur hade för effekt på den kommunala personalens sammansättning och omfattning.

Hur påverkade de olika reformerna kommunernas sätt att organisera produktionen av välfärdstjänster och vilka effekter hade de varierande lokala förutsättningarna på resultaten? Utfallet på en ort är bl a beroende av olika lokala förhållanden och faktorer som den politiska strukturen, den lokala arbetsmarknaden, ekonomiska förutsättningar, demografi (andel äldre, andel barn), lokala aktörer och den sociala strukturen inte minst vad gäller genusrelationer. 


\section{Presentation av kommunerna - urvalsprocessen}

Med hjälp av olika urvalskriterier såsom kommuntyp, politisk tradition, andel kvinnor i offentlig verksamhet, andel förvärvsarbetande kvinnor 1990, andel i offentlig sektor valdes fyra kommuner ut som fallstudieområden, nämligen Botkyrka, Gnosjö, Pajala och Kalmar. Eftersom påverkan på kvinnors arbetsmarknad var en viktig faktor valdes kommuner som representerade olika typer av näringslivsstrukturer och där offentlig sektor hade olika stor betydelse. Graden av omorganisation och en utveckling mot ett större inslag av externa entreprenörer förutsågs variera mellan kommuner med olika politisk tradition, varför den politiska majoriteten i kommunen också var en utgångspunkt. Vidare bedömde jag det som viktigt med geografisk spridning, inte minst eftersom andelen offentliganställda var större i norr än i söder.

Tabell 1:2 Undersökningskommunerna år 1990.

\begin{tabular}{|l|l|l|l|l|l|l|}
\hline Kommun & Kommuntyp & $\begin{array}{l}\text { Politisk } \\
\text { majoritet } \\
1985- \\
1995\end{array}$ & $\begin{array}{l}\text { Antal } \\
\text { invånare }\end{array}$ & $\begin{array}{l}\text { Andel kvinnor i } \\
\text { offentlig sektor } \\
\text { (inom parentes } \\
\text { primärkommunal) }\end{array}$ & $\begin{array}{l}\text { Andel } \\
\text { förvärvs- } \\
\text { arbetande } \\
\text { kvinnor }\end{array}$ & $\begin{array}{l}\text { Syssels. förändr. } \\
\text { inom offentlig } \\
\text { sektor 1990- } \\
\text { 1993, i procent } \\
\text { (inom parentes } \\
\text { primärkommunal) }\end{array}$ \\
\hline Botkyrka & $\begin{array}{l}\text { Förorts- } \\
\text { kommun }\end{array}$ & $\begin{array}{l}\text { Överv. } \\
\text { soc } \\
\text { (borg } \\
\left.91 \_94\right)\end{array}$ & 68600 & $70(41,6)$ & 77.4 & $-34,8(-27)$ \\
\hline Gnosjö & $\begin{array}{l}\text { Industri- } \\
\text { kommun }\end{array}$ & $\begin{array}{l}\text { Lång } \\
\text { borg. } \\
\text { tradition }\end{array}$ & 9900 & $32.2(21,2)$ & 81.8 & $-7(-9)$ \\
\hline Kalmar & Större stad & $\begin{array}{l}\text { Överv. } \\
\text { soc } \\
\text { (borg } \\
91-94)\end{array}$ & 56000 & $62.2(21,3)$ & 80.1 & $-20(-5)$ \\
\hline Pajala & $\begin{array}{l}\text { Glesbygds- } \\
\text { kommun }\end{array}$ & $\begin{array}{l}\text { Lång } \\
\text { soc. } \\
\text { tradition }\end{array}$ & 8414 & $74.6(47,7)$ & 69.0 & \\
\hline
\end{tabular}

Källa: Regionalstatistiska databasen

\section{Kvinnors förhandlingsläge gentemot den lokala staten}

I inledningen definieras ramen för studien som den skandinaviska välfärdsmodellen, vilken är starkt knuten till det genuskontrakt som framförhandlades mellan kvinnor, män och staten under den svenska välfärdsstatens uppbyggnad. Under 1990-talet har decentraliseringen inneburit att kvinnornas villkor på arbetsmarknaden alltmer dikteras på en lokal nivå. Den fråga som infinner sig är vilket förhandlingsläge kvinnorna har haft gentemot den lokala staten i de fyra undersökta kommunerna. Resultaten från de statistiska analyserna och analysen av intervjuerna pekar på att de lokala villkoren för kvinnorna är tämligen disparata.

I Botkyrka är förvärvsfrekvensen låg för såväl män och kvinnor vid undersökningsperiodens början men sjunker mer för kvinnor än för män. Kommunen gör drastiska nedskärningar inom den kommunala verksamheten och nedskärningarna är störst inom de kvinnodominerade yrkena, såsom barnskötare och kontorspersonal. Kommunen har en ung befolkningsstruktur men behovet av barnomsorg dämpas som en konsekvens av den låga sysselsättningsnivån och den höga arbetslösheten. Vid intervjuerna hänvisar kommunledningen till den speciella befolkningsstrukturen i Botkyrka, preciserat som "en stor andel invandrarkvinnor som är hemma med sina barn", som en bidragande orsak till att 
kommunen kunnat uppfylla barnomsorgslagen. Analysen av de personer som hade kommunen som arbetsgivare 1990 men inte 1995 visar att det finns en överrepresentation av personer med utomeuropeisk härkomst bland den avgående personalen. Sysselsättningen för kvinnorna minskar i Botkyrka och därmed minskar behovet av barnomsorg. Frågan är dock öppen om kvinnorna är hemma med sina barn frivilligt eller om de är det för att de har svårigheter att komma in på arbetsmarknaden. Problematiken är mer komplicerad än att "invandrarkvinnor" är hemma med sina barn och därför inte efterfrågar barnomsorg. På samma sätt som historieskrivningen visar att efterfrågan på all arbetskraft - inklusive gifta kvinnor - ledde till att den offentliga sektorn byggdes ut så leder tvärtom en minskad efterfrågan på kvinnlig arbetskraft till att behovet av barnomsorg minskar.

Alla fyra kommunerna uppvisar exempel på sambandet mellan behovet av kvinnor som arbetskraft och synen på den kommunala verksamheten. I Gnosjö finns det ett stort behov av all arbetskraft. Förvärvsfrekvensen är hög för både män och kvinnor och kommunledningen fastslår att för att industrihjulen ska snurra måste den kommunala servicen fungera. Vård och omsorg är även något som fastslås vara kommunala uppgifter som inte ska styras av vinstintresse. Om även detta lokala exempel tolkas i termer av förutsättningarna för den svenska välfärdsstatens uppbyggnad, så är Gnosjö kommuns situation den att all arbetskraft behövs, inklusive kvinnor med små barn, och därför måste kringservicen fungera.

I Pajala kommun är kvinnorna i mycket stor utsträckning anställda inom den offentliga sektorn. Den bild som växer fram av kvinnornas förhandlingsläge och det kontrakt som råder mellan kvinnorna i Pajala kommun och den lokala staten är mångtydigt. Utvecklingen på den lokala arbetsmarknaden i Pajala leder till att kvinnornas förvärvsfrekvens är högre än männens och männens arbetslöshet mycket högre än kvinnornas. Ur den synvinkeln kan kvinnorna betraktas som huvudförsörjare, men samtidigt är kvinnorna ofta anställda på tillfälliga kontrakt och på deltid. Det framgår också att kvinnorna använts som buffertarbetskraft i äldreomsorgen; tidigare hemarbetande kvinnor har arbetat som timanställda när kommunen har efterfrågat personal inom äldreomsorgen och dessa har inte varit registrerade som arbetslösa.

Kalmar kommun kan beskrivas som en genomsnittlig kommun där såväl befolkningsstruktur, näringslivsstruktur och sysselsättningsfrekvens ligger i nivån med riksgenomsnittet. Den har en traditionell könsuppdelning på arbetsmarknaden, där männens största näringsgren är tillverkningsindustrin, och kvinnornas hälso- och sjukvård samt sociala tjänster. I och med att kommunen prioriterar barn- och äldreomsorg, och låter de verksamheterna utvecklas efter behov, så leder könssegregeringen till att kommunen därmed också prioriterar de kvinnliga yrkesområdena. Det finns en klar uppfattning om vad som är kvinnliga och manliga yrken, som kommer till uttryck i fraser som "det är inom kvinnliga yrken som nyrekrytering skett, inte inom de manliga yrkena". Antalet sysselsatta män inom primärkommunal sektor minskar därför mer än antalet kvinnor som en följd av den könssegregerade arbetsmarknaden. Kalmarmodellen[3] är mycket intressant i sammanhanget eftersom det är en arbetsmarknadspolitisk åtgärd som från början endast var riktad till Svenska kommunalarbetarförbundets medlemmar och därmed kvinnodominerade yrkesgrupper. Åtgärden initierades visserligen centralt, men anammades av Kalmar kommun med tanke på att det var kvinnors både hel- och deltidsarbetslöshet som ökade, något man hoppades modellen skulle motverka.

\section{Genuskontraktens geografi - en öppning för vidare studier av de lokala genusstrukturernas samspel med de lokala välfärdssystemen}

Vid analyser av välfärdssystem är det av största vikt att ta med i beräkningen vilka specifika modeller som står i fokus och vad dessa har för effekter beroende på befolkningens faktiska sammansättning i termer av kön, klass och etnicitet. Andra viktiga aspekter som bör tas hänsyn till i studier av välfärdsstaten är variationerna i den lokala, i denna studie kommunala, kontext i vilken samhällsförändringar äger rum. Det nationella 
förändringsarbetet och omvärderingar av vad som är offentligt åtagande avspeglar sig i större eller mindre utsträckning på en lokal nivå. En viktig slutsats från de lokala studierna är att ingen av kommunerna kunde undgå de förändringar som initierades på den nationella nivån, men det är samtidigt klart och tydligt att det finns lokala strategier för att möta de övergripande förändringarna. Dessa strategier får effekter på de lokala genusrelationerna på arbetsmarknaden och på de lokala välfärdssystemen och därmed på det man kan kalla lokala genuskontrakt. Omvänt är de valda strategierna troligen samtidigt uttryck för de rådande sociala relationerna - inklusive genusrelationer - i det lokala samhället. Mera kunskap behövs dock för att med större precision karaktärisera kärnaspekter i utformandet av lokala genuskontrakt. Jag har i mina studier försökt fånga de formella kontrakten mellan kvinnorna och staten genom att analysera samspelet mellan de lokala välfärdssystemen och kvinnornas förhandlingsläge gentemot den lokala med särskild uppmärksamhet riktad mot förhållandena på arbetsmarknaden. Studien påvisar att kvinnors förhandlingsläge gentemot den lokala staten är en viktig del av de lokala genuskontrakten.

\section{Kvinner reiser men blir ... Velferdsmodeller og genusrelasjoner $i$ endring i Nordens utkantsområder}

I ett nystartat forskningsprogram i Nordiska ministerrådets regi ska samspelet mellan det nordiska välfärdssystemet i förändring och de lokala genuskontrakten analyseras. Projektet bygger delvis på den kunskap som uppnåtts av tidigare redovisade studier. Det är ett nordiskt samarbetsprojekt med titeln Kvinner reiser, men blir... Velferdsmodeller og genusrelasjoner i endring i Nordens utkantsområden och är geografiskt avgränsad till Nordkalotten. Titeln syftar dels på att kvinnor i Nordens ytterområden rent fysiskt reser därifrån för att exempelvis skaffa sig högre utbildning medan männen blir kvar. Men titeln syftar också till att kvinnor har uppvisat en högre flexibilitet när det gäller anpassning till den nya näringsstrukturen i ytterområdena medan männen blir kvar i traditionella yrken med få framtidsutsikter.

De svenska studierna är lokaliserade till Norrlandskommunerna. Dessa kommuner har länge brottats med hög arbetslöshet och låga sysselsättningstal. Samtidigt finns det en generell utveckling att kvinnornas sysselsättningstal kommit att bli högre än männen i de flesta av norrlandskommunerna. Pajala tjänar som ett bra exempel på en typisk norrlandskommun. Kommunen var länge dominerad av skogsindustri. Så sent som 1990 sysselsatte primärnäringarna cirka 11 procent (19 procent av männen) av de förvärvsarbetande i Pajala; 1995 hade andelen minskat till drygt sju procent av samtliga förvärvsarbetande. Skogen var männens arbetsplats sedan generationer och det har varit svårt att hitta alternativ sysselsättning åt den stora andel arbetslösa män mellan 25 och 40 år som blivit friställda från skogsarbetet. Ett stort antal statliga jobb har också gått förlorade, som exempelvis arbeten inom tullverket vilket också var en manlig arbetsplats.

Sjuttio procent av de arbetslösa i Pajala kommun är män och de flesta av dessa är mellan 25 och 50 år gamla och har som framgått arbetat inom skogs- eller byggnadsverksamhet branscher som av tradition är mansdominerade. De arbeten som arbetsförmedlingen vanligtvis får in finns inom kommunsektorn, inom vård- och omsorgsektorn eller skola vilket är kvinnodominerade branscher. Det mest utmärkande är kanske trots allt att en stor andel av de sysselsatta i kommunen har sin sysselsättning inom den offentliga sektorn. Många av dessa har arbetsförmedlingen svårt att anvisa till exempel finns det inga arbetslösa lärare. Data- och teknikföretagen, ett område där nyetableringar skett, har också svårt att hitta folk från Pajala kommun med rätt utbildning. Mitt under 1990-talets lågkonjunktur startades många småföretag med hjälp av starta eget-bidrag och det har varit jämförelsevis få konkurser. Branscherna varierar, men har det gemensamt att det främst är kvinnor som startar företagen. Det är kvinnor som startar såväl hantverksföretag, floristföretag som dataföretag.

Att kvinnorna i någon mening blir försörjarna, i alla fall sett till inkomst av förvärvsarbete gör att de lokala genusrelationerna förändras. När den svenska välfärdsmodellen byggdes 
upp var en tanken om den heltidsarbetande, fast anställde mannen med försörjningsansvar för familjen, där kvinnan möjligtvis bidrog till familjens ekonomi med deltidsarbete. Utvecklingen i Sverige visar att förändringar i det kapitalistiska systemet innebär förändringar i genuskontraktet.

\section{"Man vill ju inte var någon käring"}

Olika studier av maskulinitet och mansroller visar att männen i Norrbotten lever upp till traditionella bilder av maskulinitet och att denna maskulinitet reproduceras av den yngre generationen även om det inte är gynnsamt under rådande samhällsstruktur. Citatet ovan syftar på att Tornedalsmannen uppvisar en stor ovilja mot att göra saker som enligt de lokala normerna betraktas som kvinnogöra. De är ovilliga att skola om sig och skaffa sig ett annat yrke i rädsla över att förlora sin identitet.

Studien Kvinner reiser men bli... har det övergripande syftet att fokusera könssegregeringens betydelse för sysselsättningsutvecklingen i Norrbottens län och hur det lokala genuskontraktet påverkar och påverkas av förändringar på den postindustriella arbetsmarknaden.

(C) Susanne Johansson

\section{Referenser}

Antman, P. (red) (1993) Systemskifte: fyra folkhemsdebatter. Stockholm: Carlsson. Timbro. Esping-Andersen, G. (1991) The Three Worlds of Welfare Capitalism. Cambridge: Polity Press.

Freeman, R. Swedenborg, B. \& Topel R. (1995) Välfärdsstat i omvandling - Amerikanskt perspektiv på den svenska modellen. Nberrapporten. Stockholm: SNS (Studieförbundet Näringsliv och Samhälle).

Hirdman, Y. (1990) Genussystemet. Maktutredningen, slutrapport. SOU 1990:44

Hirdman, Y. \& Åström, G. (1992) Kontrakt i kris - Om kvinnors plats i välfärdsstaten, Carlssons bokförlag, Helsingborg.

Johansson, S. (2000) Genusstrukturer och lokala välfärdsmodeller - Fyra kommuner möter omvandlingen av den offentliga sektorn. Doktorsavhandling, Kulturgeografiska institutionen, Uppsala universitet, Geografiska regionstudier nr 40.

Lagergren, M. \& Batljan, I. \& Zavisic S. (1997) Välfärden och samhällsekonomin. Stockholm: Norstedts Tryckeri AB.

Regeringens budgetförslag (1989/90): Finansplan och sammandrag. Sammanställd och utgiven av Finansdepartementet 1989/90. Stockholm: Fritzes.

Regeringens budgetförslag 1991/92:150. Finansplan och sammandrag. Sammanställd utgiven av Regeringskansliet. Stockholm: Fritzes.

Regeringens budgetförslag 1992/1993: Finansplan och sammandrag. Sammanställd och utgiven av Regeringskansliet. Stockholm : Fritzes.

Regeringens budgetförslag (1993/1994): Finansplan och sammandrag. Sammanställd och utgiven av Finansdepartementet. Stockholm: Fritzes.

Statistiska centralbyråns årliga sysselsättningsstatistik 1990-1995. 
Berglund, A-K. Kramvig, B. \& Johansson, S. (2001) Women leave, men remain...Issues of Gender, Welfare and Labour Markets in the Nordic Periphery. Beviljad ansökan. Nordiska ministerrådet. Velferdsforskningsprogrammet.

[1] Timbro - näringlivets tankesmedja var den offentliga välfärdens största antagonister och såg det civila samhället som ett alternativ till den svenska modellen. Socialstatsprojektet och Cityuniversitetet med personer som Hans Zetterberg i förgrunden drev också en hård debatt mot den svenska modellen.

[2] Sjuk- och föräldrapenning höjdes från 75 procent till 80 procent 1998, ersättningsnivån för a-kassan sjönk från 90 till 80 procent 1993 och till 75 procent 1996 och från 1997 blev den åter 80 procent.

[3] Modellen bygger på att hel- och deltidsarbetslösa som tillhör Svenska kommunalarbetareförbundet går in som så kallade kvalitetshöjare i den ordinarie kommunala verksamheten. 